\title{
Using site-directed mutagenesis to probe the role of the D2 carotenoid in the secondary electron-transfer pathway of photosystem II
}

\author{
Katherine E. Shinopoulos $\cdot$ Jianfeng Yu • \\ Peter J. Nixon · Gary W. Brudvig
}

Received: 18 October 2012/ Accepted: 2 January 2013/Published online: 21 January 2013

(c) The Author(s) 2013. This article is published with open access at Springerlink.com

\begin{abstract}
Secondary electron transfer in photosystem II (PSII), which occurs when water oxidation is inhibited, involves redox-active carotenoids (Car), as well as chlorophylls (Chl), and cytochrome $b_{559}\left(\mathrm{Cyt} b_{559}\right)$, and is believed to play a role in photoprotection. $\mathrm{Car}_{\mathrm{D} 2}$ may be the initial point of secondary electron transfer because it is the closest cofactor to both $\mathrm{P}_{680}$, the initial oxidant, and to Cyt $b_{559}$, the terminal secondary electron donor within PSII. In order to characterize the role of $\mathrm{Car}_{\mathrm{D} 2}$ and to determine the effects of perturbing $\mathrm{Car}_{\mathrm{D} 2}$ on both the electron-transfer events and on the identity of the redox-active cofactors, it is necessary to vary the properties of $\mathrm{Car}_{\mathrm{D} 2}$ selectively without affecting the ten other Car per PSII. To this end, site-directed mutations around the binding pocket of $\mathrm{Car}_{\mathrm{D} 2}$ (D2-G47W, D2-G47F, and D2-T50F) have been generated in Synechocystis sp. PCC 6803. Characterization by near-IR and EPR spectroscopy provides the first experimental evidence that $\mathrm{Car}_{\mathrm{D} 2}$ is one of the redox-active carotenoids in PSII. There is a specific perturbation of the $\mathrm{Car}^{\bullet+}$ near-IR spectrum in all three mutated PSII samples, allowing the assignment of the spectral signature of $\mathrm{Car}_{\mathrm{D} 2}^{\bullet+}$; $\mathrm{Car}_{\mathrm{D} 2}^{\bullet+}$ exhibits a near-IR peak at
\end{abstract}

Guest Editor: Melvin Okamura

Electronic supplementary material The online version of this article (doi:10.1007/s11120-013-9793-6) contains supplementary material, which is available to authorized users.

K. E. Shinopoulos · G. W. Brudvig ( $\square)$

Department of Chemistry, Yale University, New Haven, CT 06520-8107, USA

e-mail: gary.brudvig@yale.edu

J. Yu · P. J. Nixon

Division of Molecular Biosciences, Sir Ernst Chain

Building - Wolfson Laboratories, Imperial College London,

S. Kensington campus, London SW7 2AY, UK
$980 \mathrm{~nm}$ and is the predominant secondary donor oxidized in a charge separation at low temperature in ferricyanide-treated wild-type PSII. The yield of secondary donor radicals is substantially decreased in PSII complexes isolated from each mutant. In addition, the kinetics of radical formation are altered in the mutated PSII samples. These results are consistent with oxidation of $\mathrm{Car}_{\mathrm{D} 2}$ being the initial step in secondary electron transfer. Furthermore, normal light levels during mutant cell growth perturb the shape of the $\mathrm{Chl}^{\circ+}$ near-IR absorption peak and generate a dark-stable radical observable in the EPR spectra, indicating a higher susceptibility to photodamage further linking the secondary electron-transfer pathway to photoprotection.

Keywords $\beta$-Carotene radical - Chlorophyll radical . Cytochrome $b_{559} \cdot$ EPR spectroscopy $\cdot$ Near-IR spectroscopy $\cdot$ Photosystem II $\cdot$ Site-directed mutagenesis
Abbreviations
$\beta$-DM
Car
$\mathrm{Car}^{\bullet+}$
$\mathrm{Chl}$
$\mathrm{Chl}^{\bullet+}$
$\mathrm{CP} 47$
$\beta$-Dodecylmaltoside
$\beta$-Carotene
Oxidized Car
Chlorophyll
Oxidized Chl
$47 \mathrm{kDa}$ Chlorophyll-binding protein of photosystem II
Cyt $b_{559}$
D1/D2
Cytochrome $b_{559}$
Homologous PSII reaction center core proteins
DCMU 3-(3,4-Dichlorophenyl)-1,1-dimethylurea
EPR
FWHM
Electron paramagnetic resonance
Full width at half maximum
His-tagged PSII
Synechocystis PCC 6803 PSII contain-
ing hexa-histidine-tagged CP47
MES 


$\begin{array}{ll}\text { OEC } & \begin{array}{l}\text { Oxygen-evolving complex } \\ \mathrm{P}_{680}\end{array} \\ & \text { Primary chlorophyll electron donor in } \\ \text { PSII } & \text { Pheophytin } \\ \text { PSII } & \text { Photosystem II } \\ \text { PCR } & \text { Polymerase chain reaction } \\ \mathrm{Q}_{\mathrm{A}} & \begin{array}{l}\text { Non-exchanging plastoquinone electron } \\ \text { acceptor in PSII }\end{array} \\ \mathrm{Q}_{\mathrm{B}} & \begin{array}{l}\text { Exchangeable plastoquinone electron } \\ \text { acceptor in PSII }\end{array} \\ \mathrm{WT}_{\mathrm{Z}} & \text { Wild type } \\ \mathrm{Y}_{\mathrm{Z}} / \mathrm{Y}_{\mathrm{D}} & \text { Redox-active tyrosines in the D1/D2 } \\ & \text { polypeptides }\end{array}$

\section{Introduction}

Photosystem II (PSII) is the enzyme responsible for photosyntheic oxidation of water to $\mathrm{O}_{2}$, generating the reducing equivalents that ultimately are used for $\mathrm{CO}_{2}$ fixation. Water oxidation occurs when excitons are transferred to a special group of chlorophylls, known as $\mathrm{P}_{680}$, where a charge separation occurs, as seen in Fig. 1. The electron is transferred to $\mathrm{Pheo}_{\mathrm{A}}$ on a timescale of tens of picoseconds (Holzwarth et al. 2006), and then to $\mathrm{Q}_{\mathrm{A}}$ with a timescale of 200-500 picoseconds (ps) (Rappaport and Diner 2008).
The electron-hole pair on $\mathrm{P}_{680}{ }^{+}$and $\mathrm{Q}_{\mathrm{A}}^{-}$is stable for close to $1 \mathrm{~ms}$ in cyanobacteria (Reinman et al. 1981; Gerken et al. 1989; Metz et al. 1989), during which time, under catalytic conditions, the oxygen-evolving complex (OEC) donates an electron to $\mathrm{P}_{680}{ }^{+}$via a redox-active tyrosine, $\mathrm{Y}_{\mathrm{Z}}$. Once the OEC, which consists of a $\mathrm{Mn}_{4} \mathrm{CaO}_{5}$ cluster (Umena et al. 2011), has been oxidized four times via sequential charge separations to reach a high-valent state, probably $\mathrm{Mn}(\mathrm{IV}) \mathrm{Mn}(\mathrm{IV}) \mathrm{Mn}(\mathrm{IV}) \mathrm{Mn}(\mathrm{IV})-\mathrm{O}^{\bullet} \quad$ (Siegbahn 2006; Sproviero et al. 2008), it is capable of oxidizing water to dioxygen. Meanwhile, the electron on $\mathrm{Q}_{\mathrm{A}}$ is transferred to $\mathrm{Q}_{\mathrm{B}}$, which dissociates away from PSII after two reductions and subsequent protonations, carrying reducing equivalents to the next step in photosynthesis and ultimately resulting in the storage of energy in the chemical bonds of sugars.

However, the intermediates associated with water splitting are very oxidizing, and cause damage to the protein over time. The D1 subunit of PSII, which contains most of the cofactors involved in water oxidation, turns over every $30 \mathrm{~min}$, in a process that involves disassembly of the PSII complex, membrane diffusion, and protein synthesis (Nixon et al. 2010). In order to minimize damage, PSII has evolved multiple mechanisms of photoprotection to prolong the lifetime of its subunits and minimize energy expenditure for protein synthesis. One mechanism involves adjusting the size of the light-harvesting antenna; other mechanisms involve dissipating excess solar energy as

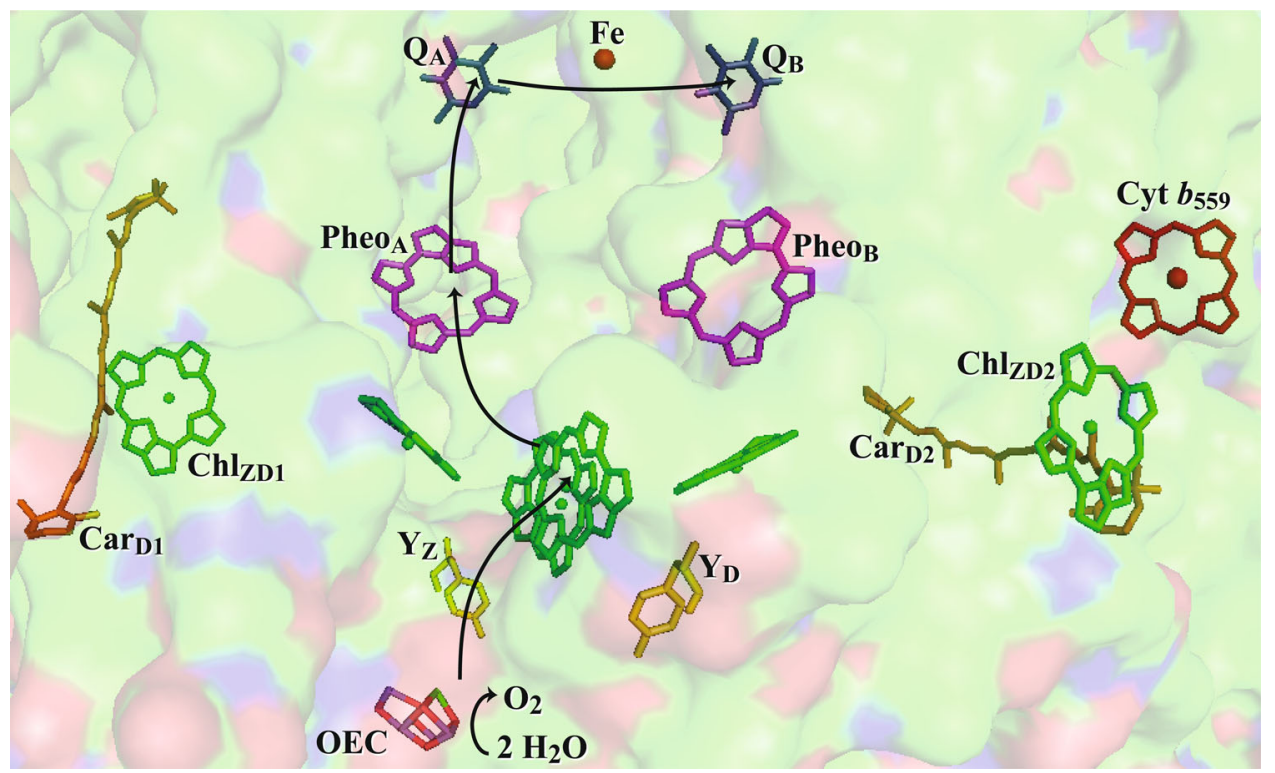

Fig. 1 The arrangement of cofactors in the D1/D2/Cyt $b_{559}$ subcomplex of cyanobacterial PSII, viewed along the membrane plane (PDB ID: 3ARC). Black arrows represent electron transfer. The oxygen-evolving complex (OEC) is shown with manganese ions in purple, oxygen in red, and calcium in green; tyrosine $\mathrm{Z}\left(\mathrm{Y}_{\mathrm{Z}}\right)$ and tyrosine $\mathrm{D}\left(\mathrm{Y}_{\mathrm{D}}\right)$ are shown in yellow; chlorophylls $(\mathrm{Chl})$ are shown in green; $\beta$-carotenes $(\mathrm{Car})$ are shown in orange; pheophytins $\left(\mathrm{Pheo}_{\mathrm{A}}\right.$ and $\left.\mathrm{Pheo}_{\mathrm{B}}\right)$ are shown in magenta; quinones $\left(\mathrm{Q}_{\mathrm{A}}\right.$ and $\left.\mathrm{Q}_{\mathrm{B}}\right)$ are shown in blue; and cytochrome $b_{559}\left(\mathrm{Cyt} b_{559}\right)$ and the nonheme iron are shown in red. The surface of the protein is shown in the background and colored according to atom identity with $\mathrm{C}$ in green, $\mathrm{N}$ in blue, and $\mathrm{O}$ in red 
heat, as in the xanthophyll cycle in plants (Niyogi 1999) or via the orange carotenoid protein in cyanobacteria (Kirilovsky and Kerfeld 2012). In addition, when water-oxidation catalysis is impaired, oxidation of secondary donors, including carotenoids (Car), chlorophylls (Chl), and cytochrome $b_{559}$ (Cyt $b_{559}$ ), may serve to remove excess oxidizing equivalents from PSII (Thompson and Brudvig 1988; Buser et al. 1992) or to quench chlorophyll excited states (Schweitzer and Brudvig 1997).

Of the secondary electron donors, Cyt $b_{559}$ has the lowest reduction potential, which is interestingly variable from $390 \mathrm{mV}$ to as low as $-150 \mathrm{mV}$ (Thompson et al. 1989; Stewart and Brudvig 1998). Cyt $b_{559}$ is, therefore, the terminal secondary electron donor within PSII. It may additionally be rereduced by the plastoquinone pool, leading to a cyclic process for the removal of excess, damaging oxidizing equivalents from PSII when the system is unable to drive water oxidation (Shinopoulos and Brudvig 2012).

Although the final location of the oxidizing equivalent passed along the secondary electron-transfer pathway has been determined to be Cyt $b_{559}$ (Vermeglio and Mathis 1974; de Paula et al. 1985), the pathway of electron transfer from Cyt $b_{559}$ to $\mathrm{P}_{680}{ }^{+}$has not been fully characterized. The distance of about $40 \AA$ between the two cofactors indicates that they do not participate in direct electron transfer, and it has indeed been observed that $\mathrm{Chl}$ and Car are intermediates (de Paula et al. 1985; Hanley et al. 1999; Vrettos et al. 1999; Tracewell et al. 2001; Faller et al. 2001). It has also been shown that there are at least two redox-active carotenoids $\left(\mathrm{Car}^{\bullet+}\right)$ in PSII based on the shift of the $\mathrm{Car}^{\bullet+}$ near-IR peak over a range of illumination temperatures and the wavelength-dependant decay rate of the $\mathrm{Car}^{\bullet+}$ absorbance (Tracewell and Brudvig 2003; Telfer et al. 2003). There are as many as 5 redox-active $\mathrm{Chl}$ $\left(\mathrm{Chl}^{\bullet+}\right)$ (Tracewell and Brudvig 2008; Telfer et al. 1990), with one ligated to D1-His 118 (Stewart et al. 1998). However, there are $11 \mathrm{Car}$ and $35 \mathrm{Chl}$ per PSII, as seen in Fig. 2, and most of the redox-active cofactors have not been specifically identified. Some $\mathrm{Chl}^{\bullet+}$ may be in $\mathrm{CP} 43$ and CP47, peripheral subunits that bind many Chl molecules (Tracewell and Brudvig 2008). In regard to the two $\mathrm{Car}^{\bullet+}$, it has been observed that the average distance from the nonheme iron to the two $\mathrm{Car}^{\bullet+}$ is $38 \AA$, and it has been hypothesized that one $\mathrm{Car}^{\bullet+}$ is $\mathrm{Car}_{\mathrm{D} 2}^{\circ+}$ (Lakshmi et al. 2003; Tracewell and Brudvig 2003). This seems likely, because $\mathrm{Car}_{\mathrm{D} 2}$ is the closest cofactor to both $\mathrm{P}_{680}$ and Cyt $b_{559}$, with edge-to-edge distances of 11 and $12 \AA$, respectively. The oxidation of $Y_{D}$ results in a shift of the $\mathrm{Car}^{\bullet+}$ near-IR peak, indicating proximity of at least one $\mathrm{Car}^{\circ+}$ to $\mathrm{Y}_{\mathrm{D}}$ (Tracewell and Brudvig 2003), although electrochromic effects can propagate significant distances though PSII (Stewart et al. 2000). A relatively higher yield of $\mathrm{Car}^{\bullet+}$ than $\mathrm{Chl}^{\bullet+}$ is observed at lower temperatures, with increased $\mathrm{Chl}^{\bullet+}$ at higher temperatures, also indicating that $\mathrm{Car}^{\bullet+}$ is closer than $\mathrm{Chl}^{\bullet+}$ to $\mathrm{P}_{680}$ (Hanley et al. 1999).

In order to evaluate the role of $\mathrm{Car}_{\mathrm{D} 2}$ in secondary electron transfer relative to the roles of other Car in PSII, we have characterized the effects of site-directed mutations around the binding pocket of $\mathrm{Car}_{\mathrm{D} 2}$ (see Fig. 3). In this study, the effects of the mutations D2-G47W, D2-T50F, and D2-G47F on the secondary electron-transfer pathway
Fig. 2 The arrangement of cofactors in PSII, viewed from the membrane surface (PDB ID: 3ARC). The oxygen-evolving complex (OEC) is shown with manganese atoms in purple, oxygen in red, and calcium in green; tyrosine $\mathrm{Z}\left(\mathrm{Y}_{\mathrm{Z}}\right)$ and tyrosine $\mathrm{D}\left(\mathrm{Y}_{\mathrm{D}}\right)$ are shown in yellow; chlorophylls (Chl) are shown in green; $\beta$-carotenes (Car) are shown in orange; pheophytins $\left(\mathrm{Pheo}_{\mathrm{A}}\right.$ and $\left.\mathrm{Pheo}_{\mathrm{B}}\right)$ are shown in magenta; quinones $\left(\mathrm{Q}_{\mathrm{A}}\right.$ and $\left.\mathrm{Q}_{\mathrm{B}}\right)$ are shown in blue; and cytochrome $b_{559}$ (Cyt $b_{559}$ ) and the nonheme iron are shown in red. The surface of the protein is shown in the background and colored according to atom identity with $\mathrm{C}$ in green, $\mathrm{N}$ in blue, and $\mathrm{O}$ in red

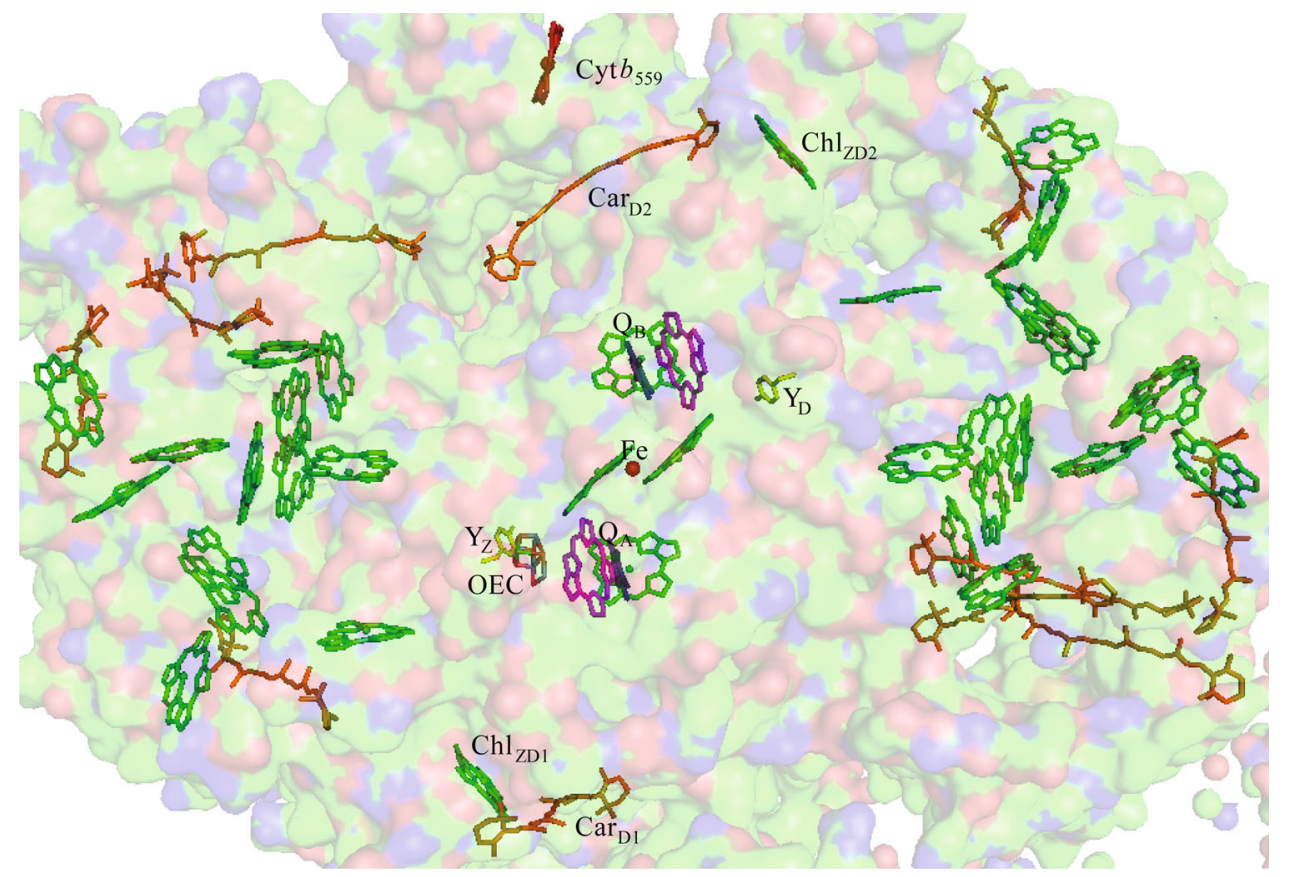



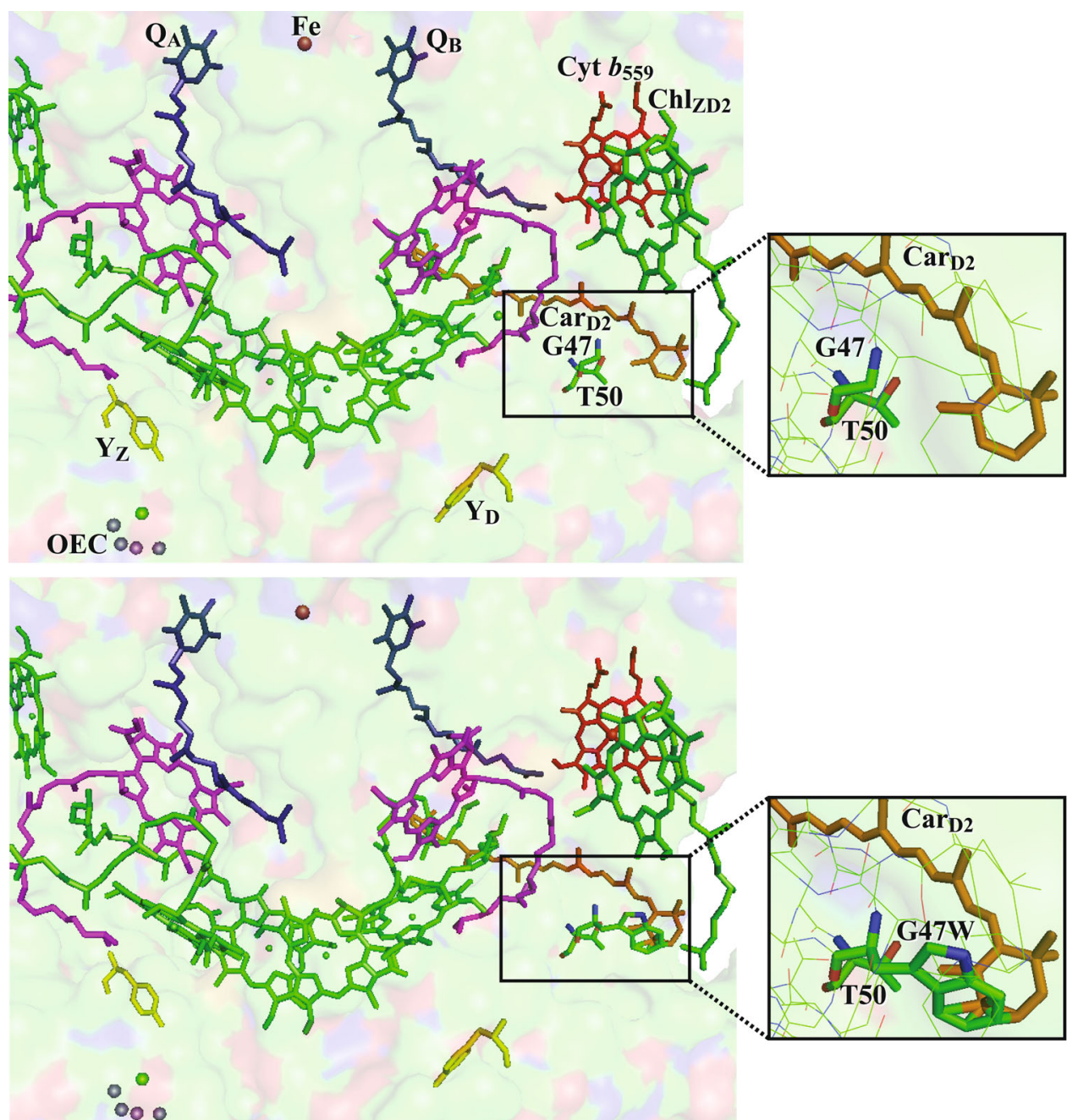

Fig. 3 Electron-transfer cofactors in photosystem II, viewed along the membrane plane (PDB ID: 2AXT). The oxygen-evolving complex (OEC) is shown with manganese atoms in purple and calcium in green; tyrosine $\mathrm{Z}\left(\mathrm{Y}_{\mathrm{Z}}\right)$ and tyrosine $\mathrm{D}\left(\mathrm{Y}_{\mathrm{D}}\right)$ are shown in yellow; chlorophylls $(\mathrm{Chl})$ are shown in green; $\beta$-carotene (Car) is shown in orange; pheophytins $\left(\mathrm{Pheo}_{\mathrm{A}}\right.$ and $\left.\mathrm{Pheo}_{\mathrm{B}}\right)$ are shown in magenta; quinones $\left(\mathrm{Q}_{\mathrm{A}}\right.$ and $\left.\mathrm{Q}_{\mathrm{B}}\right)$ are shown in blue; and cytochrome $b_{559}$ (Cyt $b_{559}$ ) and the nonheme iron are shown in red. The surface of the protein is shown in the background and colored according to atom

are examined by low temperature near-IR optical and EPR spectroscopy.

\section{Materials and methods}

Chemicals and reagents

2-(N-morpholino)-ethanesulfonic acid (MES) was purchased from USB Corporation. $\beta$-Dodecyl maltoside ( $\beta$-DM) was purchased from Enzo Life Sciences International Inc. A stock solution $(80 \mathrm{mM}$ ) of potassium ferricyanide (purchased from Sigma-Aldrich) was prepared in buffer and frozen until use. identity with $\mathrm{C}$ in green, $\mathrm{N}$ in blue, and $\mathrm{O}$ in red. Top A model of WT PSII structure, containing D2-G47 and D2-T50 modeled in stick form. Inset an enlarged picture of $\mathrm{G} 47, \mathrm{~T} 50$, and the $\beta$-ionylidene ring of $\mathrm{Car}_{\mathrm{D} 2}$ with the surrounding residues shown as lines, colored according to atom identity. Bottom A model of D2-G47W, with G47W and T50 modeled in stick form. Inset an enlarged picture of G47W, T50, and the $\beta$-ionylidene ring of $\mathrm{Car}_{\mathrm{D} 2}$ with the surrounding residues shown as lines, colored according to atom identity

Mutagenesis

D2 mutants were constructed according to (Tang et al. 1993) except that the recipient strain Tol145/CP47-His, obtained by transforming strain Tol145 (Tang et al. 1993) with genomic DNA from strain PSII-His (Boehm et al. 2011), also encoded a C-terminal His-tagged derivative of CP47. Plasmid pDC074 was used as the parental vector for site-directed mutagenesis (Tang et al. 1993). Mutations were introduced into the plasmid by overlap-extension PCR so that the codon specifying D2-G47 was replaced by either TGG (to make mutated D2-G47W) or TTC (D2$\mathrm{G} 47 \mathrm{~F}$ ) and the codon specifying D2-T50 was replaced by 
TTC (D2-T50F). In all three cases, the codon for Leu45 (CTG) was mutated to incorporate a silent mutation (CTA), in order to create a unique restriction site, AvrII, to help screen for mutations. The genotypes of the cyanobacterial mutants were confirmed by PCR analysis and DNA sequencing.

\section{Cell growth and protein purification}

Cells were grown initially on plates containing $5 \mathrm{mM}$ glucose, $10 \mu \mathrm{M}$ DCMU, $25 \mathrm{mg} / \mathrm{L}$ kanamycin, and $10 \mathrm{mg} / \mathrm{L}$ erythromycin. In liquid culture, the cells were grown without antibiotics in the presence of $5 \mathrm{mM}$ glucose under 10 or $40 \mu$ Einsteins $/ \mathrm{m}^{2} / \mathrm{s}$ of illumination, as noted. Histagged PSII core particles were isolated from Synechocystis PCC 6803 cells as previously described (Lakshmi et al. 2002).

\section{Sample treatments}

For low-temperature measurements, PSII samples were transferred to a buffer containing $15 \mathrm{mM} \mathrm{CaCl}_{2}, 63 \%$ (v/v) glycerol, and $50 \mathrm{mM}$ MES at $\mathrm{pH}$ 6.0. Prior to freezing, PSII samples were treated with $5 \mathrm{mM}$ ferricyanide to oxidize Cyt $b_{559}$.

\section{Near-IR optical spectroscopy}

A Perkin-Elmer Lambda 20 spectrometer was used to make optical spectroscopic measurements in the visible and nearIR. Low-temperature optical measurements were made with an Oxford Instruments Optistat liquid helium cryostat. Polyethylene cuvettes with a $1.0 \mathrm{~cm}$ path length and $0.4 \mathrm{~cm}$ width (Fisher Scientific) were used for low-temperature optical measurements. A $150 \mathrm{~W}$ quartz-halogen lamp filtered by a 6 in water filter and a heat-absorbing filter (Schott KG-5) was used to illuminate samples. A Schott-Fostec randomized fiber optic bundle was used to direct the light into the cryostat. The PSII samples were prepared as previously described (Tracewell and Brudvig 2008). Illumination for 15 min was performed on samples that were equilibrated at the specified temperature for at least $60 \mathrm{~min}$ in the cryostat. All spectra collected after illumination are referenced to the dark spectrum measured at the same temperature to avoid contributions from spectral changes in the background due to temperature effects.

Spectral simulations

The program Igor Pro 6.2 was used to simulate the near-IR absorption data, to analyze the decay kinetics, and to plot all spectra.
EPR spectroscopy

X-band EPR measurements were conducted on a Bruker ELEXSYS E500 EPR spectrometer equipped with an Oxford ESR 900 He-flow cryostat and a Super High Q cavity. Samples were illuminated by a xenon halogen lamp filtered by a 6 in water filter and a heat-absorbing filter, with a fiber optic cable directing light into the cryostat. Radical yields per PSII were determined by integration of the derivative EPR signals and calibrated to photooxidized tyrosine $\mathrm{D}\left(\mathrm{Y}_{\mathrm{D}}^{\bullet}\right)$. $\mathrm{Y}_{\mathrm{D}}^{\bullet}$ was generated by illuminating the PSII samples for $30 \mathrm{~s}$ at $0{ }^{\circ} \mathrm{C}$, incubating on ice for $2 \mathrm{~min}$, and freezing in total darkness.

\section{Results}

Selection of mutations

The mutations D2-G47F, D2-G47W, and D2-T50F were selected by using Coot, a modeling program that includes the ability to mutate a selected residue from a known crystal structure (Emsley and Cowtan 2004). The mutated residue is placed in the conformation in which it is typically found, and other conformations are also observable. Using the 3.0- $\AA$ resolution crystal structure of PSII (Loll et al. 2005), which was focused on accurate cofactor positioning and found similar locations to the recent $1.9-\AA$ resolution structure (Umena et al. 2011), residues that would sterically interfere with $\mathrm{Car}_{\mathrm{D} 2}$ binding were identified, as shown in Fig. 3. Aromatic residues have been observed around the $\beta$-ionylidene ring binding site (Tracewell and Brudvig 2003), which has been found to be important for function (Bautista et al. 2005), and because the Car chain exists in a variety of conformations in PSII samples, the area near the rings was targeted for mutation. In this way, several mutations were identified that may cause a disruption to the hydrophobic binding pocket of the $\beta$-ionylidene ring of $\mathrm{Car}_{\mathrm{D} 2}$.

\section{Near-IR Optical Spectroscopy}

WT, D2-T50F, D2-G47W, and D2-G47F His-tagged PSII complexes were illuminated in a cryostat at $20 \mathrm{~K}$ for $15 \mathrm{~min}$, maximally generating one stable charge separation per PSII center; at this temperature in ferricyanide-treated samples, the stable charge separation results in an electron on $\mathrm{Q}_{\mathrm{A}}^{-}$and a hole that is located on either a Car neutral radical ( $\mathrm{Car}^{\circ}$ absorbing at $750 \mathrm{~nm})$, a Chl cation radical $\left(\mathrm{Chl}^{\bullet+}\right.$ absorbing at $800-840 \mathrm{~nm})$ or a Car cation radical $\left(\mathrm{Car}^{\bullet+}\right.$ absorbing near $1,000 \mathrm{~nm}$ ), as seen in Fig. 4. For each mutated PSII sample, the total yield of stable charge separated states was lower than in WT PSII samples when normalized to the same 

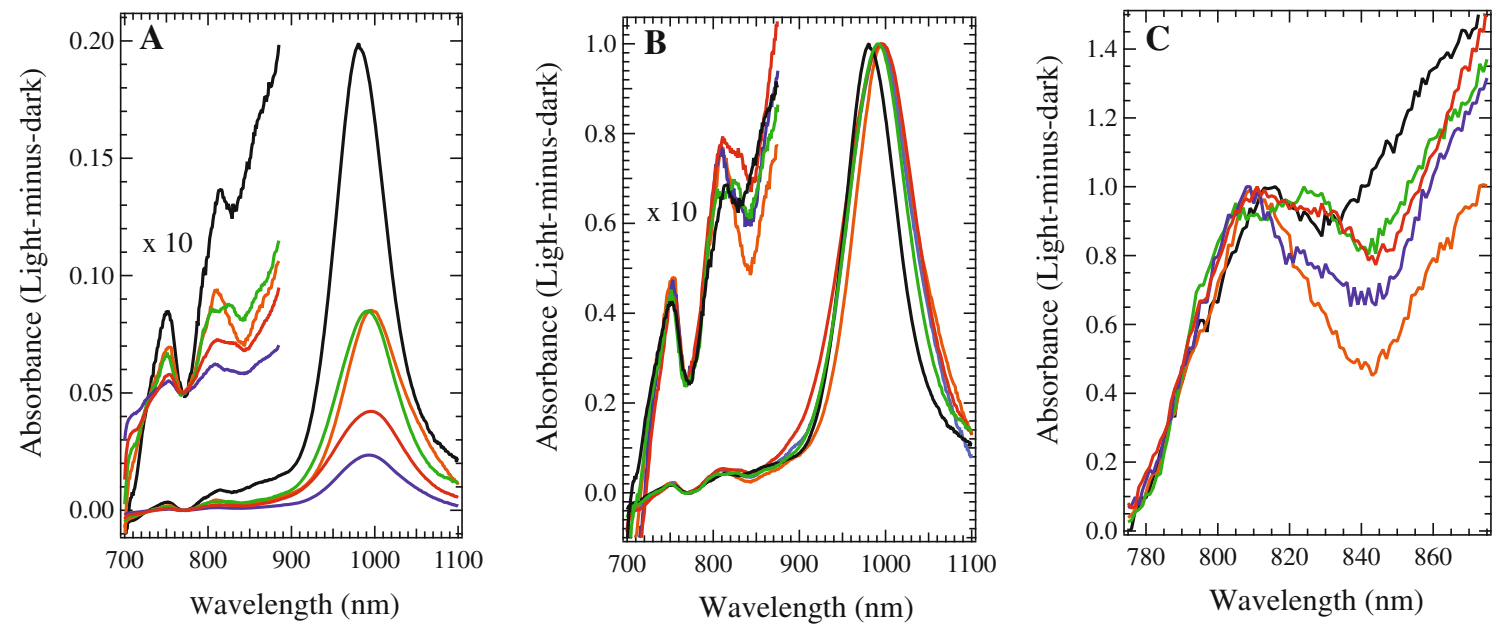

Fig. 4 Light-minus-dark near-IR spectra of Synechocystis PSII samples from WT cells grown under $40 \mu$ Einsteins $/ \mathrm{m}^{2} / \mathrm{s}$ of illumination (black), T50F cells grown under $10 \mu$ Einsteins $/ \mathrm{m}^{2} / \mathrm{s}$ of illumination (green), T50F cells grown under $40 \mu$ Einsteins $/ \mathrm{m}^{2} / \mathrm{s}$ (orange), G47W cells grown under $10 \mu$ Einsteins $/ \mathrm{m}^{2} / \mathrm{s}$ of

Table 1 The peak parameters of the two Gaussian components of the $\mathrm{Car}^{\bullet+}$ peak present in WT, T50F, G47F, and G47W PSII samples

\begin{tabular}{lllllll}
\hline & $\begin{array}{l}\lambda_{1} \\
(\mathrm{~nm})\end{array}$ & $\begin{array}{l}\text { Initial } \\
\%\end{array}$ & $\begin{array}{l}\mathrm{FWHM}_{1} \\
(\mathrm{~nm})\end{array}$ & $\begin{array}{l}\lambda_{2} \\
(\mathrm{~nm})\end{array}$ & $\begin{array}{l}\text { Initial } \\
\%\end{array}$ & $\begin{array}{l}\mathrm{FWHM}_{2} \\
(\mathrm{~nm})\end{array}$ \\
\hline WT & 980.4 & 69 & 37.9 & 999.2 & 31 & 74.1 \\
T50F & 989.3 & 68 & 43.2 & 999.8 & 32 & 92.8 \\
G47F & 988.3 & 48 & 40.8 & 1001 & 52 & 68.0 \\
G47W & 993.3 & 82 & 55.0 & 1003 & 17 & 127 \\
\hline
\end{tabular}

concentration of $\mathrm{Chl}$, indicated by the lower yield of all secondary donors $\left(\mathrm{Car}^{\bullet}, \mathrm{Chl}^{\bullet+}\right.$, and $\left.\mathrm{Car}^{\bullet+}\right)$, seen in Fig. 4A. When the magnitudes of the $\mathrm{Car}^{\bullet+}$ peaks are normalized to 1 , as in Fig. 4B, it can be seen that the $\mathrm{Car}^{\circ+}$ peak is slightly red shifted and has a larger FWHM in mutated PSII samples compared to WT PSII samples. The yield of the Car peak at $750 \mathrm{~nm}$ tracks with the magnitude of the $\mathrm{Car}^{\bullet+}$ peak, reinforcing that it is generated from Car (Gao et al. 2009). In the mutated PSII samples, there is slightly more $\mathrm{Chl}^{\bullet+}$ generated relative to $\mathrm{Car}^{\bullet+}$ than in WT, especially in the G47F and G47W PSII samples, with an absorbance centered at $825 \mathrm{~nm}$. Although the yield of $\mathrm{Chl}^{\bullet+}$ appears to be very low, it has an extinction coefficient of about 7,000 $\mathrm{M}^{-1} \mathrm{~cm}^{-1}$ (Borg et al. 1970), while $\mathrm{Car}^{\bullet+}$ has an extinction coefficient of about $160,000 \mathrm{M}^{-1} \mathrm{~cm}^{-1}$ (Tan et al. 1997). The width and shape of the $\mathrm{Chl}^{\bullet+}$ peak varies among the samples, as seen in Fig. 4C. The T50F PSII sample isolated from cells grown at $10 \mu$ Einsteins $/ \mathrm{m}^{2} / \mathrm{s}$ of illumination has the narrowest peak, followed closely by G47F PSII samples. PSII samples isolated from G47W, T50F grown under $40 \mu$ Einsteins $/ \mathrm{m}^{2} / \mathrm{s}$ of illumination, and WT cells display wider $\mathrm{Chl}^{\bullet+}$ signatures that appear to contain two peaks. illumination ( $r e d$ ), and G47F cells grown under $40 \mu$ Einsteins $/ \mathrm{m}^{2} / \mathrm{s}$ of illumination (blue), recorded at $20 \mathrm{~K}$. A Normalized to equal chlorophyll concentration. B Each $\mathrm{Car}^{\bullet+}$ peak normalized to 1 . C Each $\mathrm{Chl}^{\bullet+}$ peak normalized to 1

Using global analysis in Igor Pro 6.2, the $\mathrm{Car}^{\bullet+}$ peak in all PSII samples was deconvoluted into two Gaussian contributions. One contribution had a maximum at $999-1,003 \mathrm{~nm}$, while the other varied from $980 \mathrm{~nm}$ in WT PSII to $993 \mathrm{~nm}$ in G47W PSII, as seen in Table 1. The FWHM of the Gaussian components were, in general, larger in the mutated PSII samples, with the widest peaks appearing in the G47 W PSII spectrum.

The relative amounts of the longer-wavelength component and shorter-wavelength component varied among the WT and mutated PSII samples, with the G47F PSII spectrum containing the most longer-wavelength component, the G47W spectrum containing the least longer-wavelength component, and the WT and T50F spectra containing a similar ratio to each other, as seen in Table 1; Figs. 5 and 6. In addition, in each PSII sample, the shorter-wavelength component of the $\mathrm{Car}^{\bullet+}$ peak decayed more quickly and to a larger extent. Therefore, there was a larger proportion of the longer-wavelength component present at longer times.

\section{EPR Spectroscopy}

Following the generation of $\mathrm{Y}_{\mathrm{D}}^{\circ}$, EPR spectra of WT, D2T50F, D2-G47W, and D2-G47F PSII samples were collected in total darkness at $30 \mathrm{~K}$, as seen in Fig. 7. The lineshapes vary slightly among the spectra. The spectra of T50F PSII grown at $10 \mu$ Einsteins $/ \mathrm{m}^{2} / \mathrm{s}$ of illumination exhibit the most characteristic $\mathrm{Y}_{\mathrm{D}}^{\bullet}$ pattern. The WT spectrum also matches the lineshape reported in the literature for $\mathrm{Y}_{\mathrm{D}}^{\bullet}$ (Un et al. 1996; Tang et al. 1993; Noren et al. 1991). However, the spectra of PSII isolated from G47 W, T50F grown at $40 \mu$ Einsteins $/ \mathrm{m}^{2} / \mathrm{s}$ of illumination, and $\mathrm{G} 47 \mathrm{~F}$ 

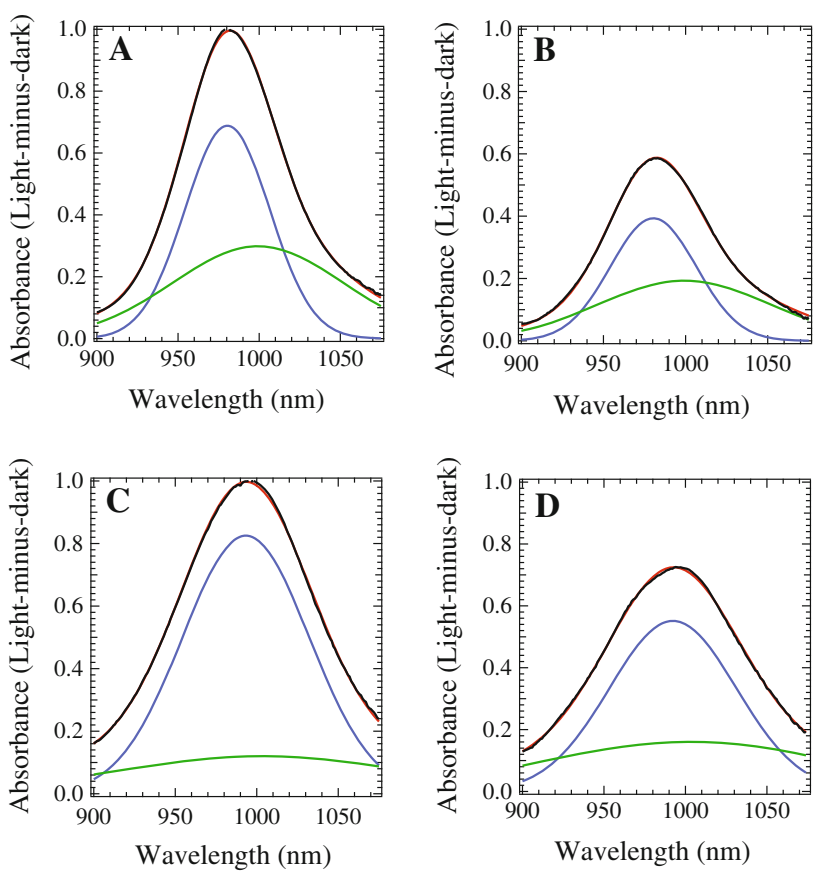

Fig. 5 Gaussian deconvolutions of the $\mathrm{Car}^{\bullet+}$ peak formed by illumination for $15 \mathrm{~min}$ at $20 \mathrm{~K}$. A The WT PSII difference spectrum after $0 \mathrm{~min}$ of dark incubation. B The WT PSII difference spectrum after $3 \mathrm{~h}$ of dark incubation. C The G47W PSII difference spectrum after 0 min of dark incubation. D The G47W PSII difference spectrum after $3 \mathrm{~h}$ of dark incubation. The two Gaussian components from Table 1 are shown in blue (shorter-wavelength component) and green (longer-wavelength component), their sum is shown in red, and the raw data are shown in black
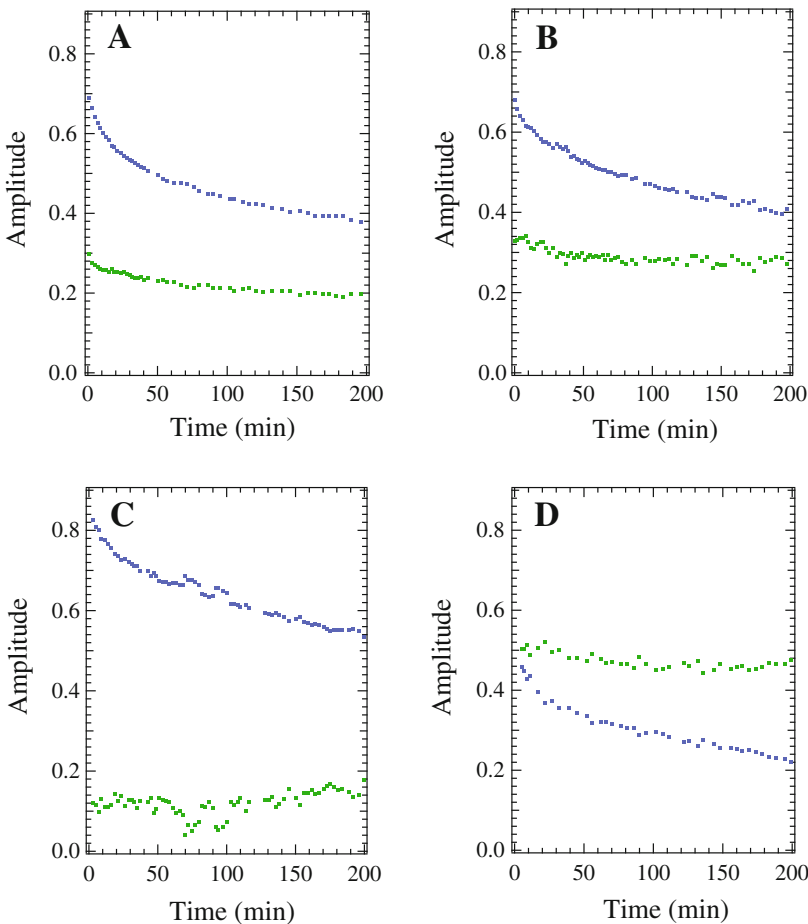

Fig. 6 The decay in absorbance, as a function of dark incubation time, of the shorter-wavelength component (blue) and the longerwavelength component (green). A WT PSII samples. B T50F PSII samples. C G47W PSII samples. D G47F PSII samples

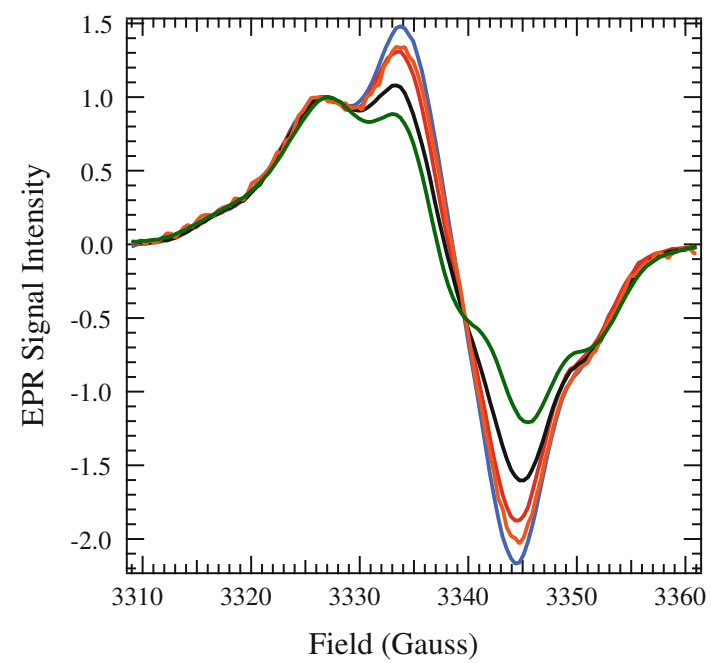

Fig. 7 EPR spectra in the $\mathrm{Y}_{\mathrm{D}}^{\bullet}$ region of PSII isolated from WT cells grown under $40 \mu$ Einsteins $/ \mathrm{m}^{2} / \mathrm{s}$ of illumination (black), T50F cells grown under $10 \mu$ Einsteins $/ \mathrm{m}^{2} / \mathrm{s}$ of illumination (green), T50F cells grown under $40 \mu$ Einsteins $/ \mathrm{m}^{2} / \mathrm{s}$ (orange), G47W cells grown under $40 \mu$ Einsteins $/ \mathrm{m}^{2} / \mathrm{s}$ of illumination ( $r e d$ ), and G47F cells grown under $40 \mu$ Einsteins $/ \mathrm{m}^{2} / \mathrm{s}$ of illumination (blue). Instrument settings: temperature, $30 \mathrm{~K}$; microwave power, $105 \mu \mathrm{W}$; and field modulation amplitude, $4 \mathrm{G}$

cells deviate increasingly from a normal $\mathrm{Y}_{\mathrm{D}}^{\bullet}$ spectrum. The shift could be due to a change in the orientation of the methylene protons with respect to the ring in the tyrosyl radicals of the mutated PSII samples, resulting in altered hyperfine coupling (Barry and Babcock 1998). However, due to the shift in $g$ value of the baseline crossing point toward the free-electron $g$ value and the consistency of the most upfield and downfield hyperfine peaks, it appears that the change in lineshape is due to an organic radical signal overlapping with $\mathrm{Y}_{\mathrm{D}}^{\circ}$. Although this is consistent with the presence of $\mathrm{Chl}^{\bullet+}$ and $\mathrm{Car}^{\bullet+}$, which may be generated by illumination, these species have a very short lifetime at $0{ }^{\circ} \mathrm{C}$, and would have typically decayed during dark incubation. In addition, there is a larger amount of the organic radical signature present in the spectrum from T50F grown at $40 \mu$ Einsteins $/ \mathrm{m}^{2} / \mathrm{s}$ of illumination than is present in the spectrum from T50F grown at $10 \mu$ Einsteins $/ \mathrm{m}^{2} / \mathrm{s}$ of illumination, indicating that the presence of an overlapping radical EPR signal is due to an effect of high light during growth of the cells rather than an effect of the mutation on the structure of $\mathrm{Y}_{\mathrm{D}}^{\circ}$.

The samples containing $\mathrm{Y}_{\mathrm{D}}^{\circ}$ were subsequently illuminated in the cryostat at $30 \mathrm{~K}$ for $60 \mathrm{~min}$ and spectra were recorded during the illumination, as seen in Figs. 8 and 9. During the illumination, $\mathrm{Chl}^{\bullet+}$ and $\mathrm{Car}^{\bullet+}$ (Figs. 8 and 9), which have indistinguishable $g$ values at $\mathrm{X}$ band (Hanley et al. 1999), and some oxidized Cyt $b_{559}$ (data not shown) were formed. For the WT PSII sample (Fig. 8A), the total yield of oxidized secondary donors was generated within 


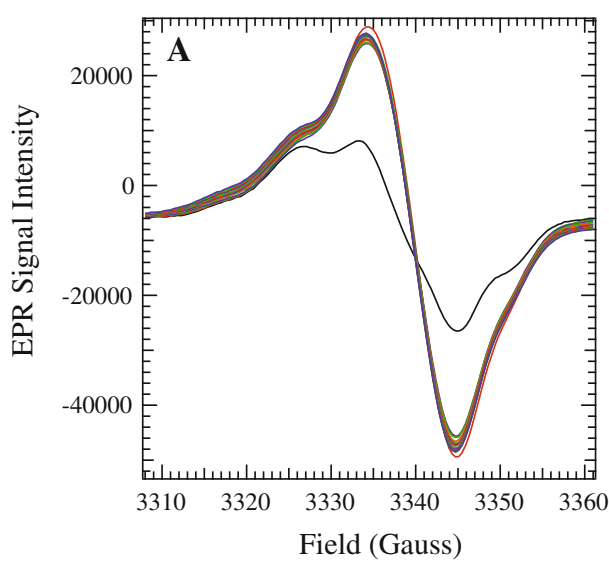

Fig. 8 The EPR spectra collected as samples were illuminated in the cryostat with a xenon lamp for $1 \mathrm{~h}$. A WT spectra collected in the dark (black) and after 0 (red), 5 (green), 10 (blue), 15 (red), 20 (green), 25 (blue), 30 (blue), 35 (red), 40 (green), 45 (blue), 50 (red), 55 (green), and 60 (blue) minutes of illumination. B G47F spectra

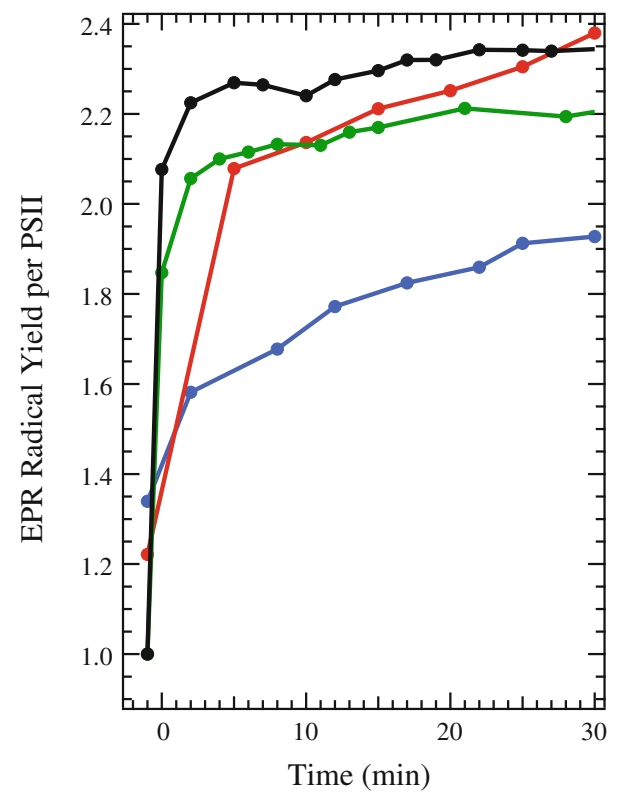

Fig. 9 The radical yield per PSII as a function of illumination time, obtained by double integration of the EPR spectra of WT (black), T50F (green), G47W (red), and G47F (blue) PSII samples, recorded at $30 \mathrm{~K}$. Instrument settings as in Fig. 7

5 min of illumination. In contrast, in the G47F PSII sample (Fig. 8B), the maximum yield of oxidized secondary donors was not reached until after $30 \mathrm{~min}$ of illumination.

The procedure for generating $\mathrm{Y}_{\mathrm{D}}^{\bullet}$ results in one darkstable $\mathrm{Y}_{\mathrm{D}}^{\bullet}$ per PSII, formed on ice before the sample is frozen for measurement of the EPR spectrum. Double integration of the $\mathrm{Y}_{\mathrm{D}}^{\circ} \mathrm{EPR}$ spectra gives the area corresponding to one radical per PSII center, once it has been corrected for any other overlapping organic radical signals. Under illumination at cryogenic temperatures, PSII is

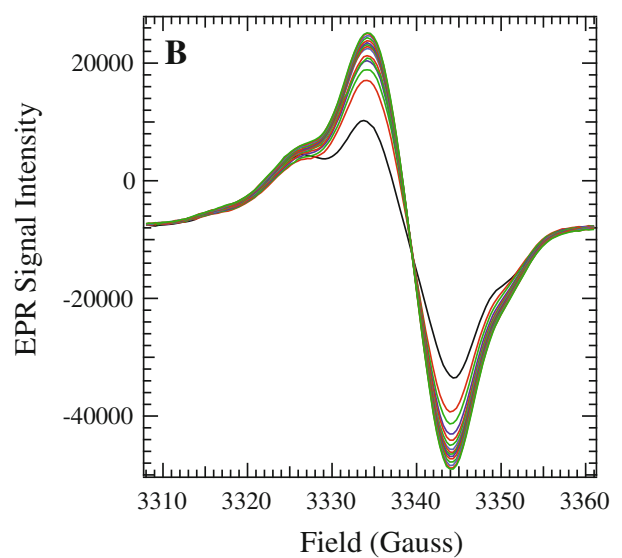

collected in the dark (black) and after 2 (red), 8 (green), 12 (blue), 17 (red), 22 (green), 25 (blue), 30 (red), 34 (green), 38 (blue), 42 (red), 47 (green), 51 (blue), 55 (red), and 60 (green) minutes of illumination. Instrument settings as in Fig. 7

limited to one charge separation, and a second EPR signal is generated from the electron donor in each PSII center. Therefore, there should be a total of two oxidized species on the electron donor side of PSII for each PSII center: one $\mathrm{Y}_{\mathrm{D}}^{\bullet}$ and either $\mathrm{Chl}^{\bullet+}, \mathrm{Car}^{\bullet}, \mathrm{Car}^{\bullet+}$, or oxidized Cyt $b_{559}$. However, the kinetics of formation of the second radical varied among the WT and mutated PSII samples, as seen in Fig. 9. WT and T50F samples generated the full radical yield within a few minutes of illumination. G47W samples took slightly longer to reach the total yield, while G47F samples reached two radicals per PSII only after a full $60 \mathrm{~min}$ of illumination (data from 30 to $60 \mathrm{~min}$ not shown).

\section{Discussion}

$\mathrm{Car}_{\mathrm{D} 2}$ occupies a position between $\mathrm{P}_{680}$, the initial oxidant, and Cyt $b_{559}$, the terminal electron donor, in the path of secondary electron transfer. Removing or disrupting this cofactor would be expected to alter the electron-transfer properties of PSII, if $\mathrm{Car}_{\mathrm{D} 2}$ is involved as an early donor in the secondary electron-transfer pathway. Indeed, the yields and kinetics of $\mathrm{Car}$ and $\mathrm{Chl}$ radical formation are altered in PSII samples that have been mutated to alter D2-G47 and D2-T50, two amino acids near $\mathrm{Car}_{\mathrm{D} 2}$. We have studied the properties of these mutated PSII complexes in which $\mathrm{Car}_{\mathrm{D} 2}$ is perturbed in order to gain more information on the secondary electron-transfer cofactors and their connectivity.

At cryogenic temperatures, illumination generates one stable charge separation per PSII, resulting in the formation of $\mathrm{Q}_{\mathrm{A}}^{-}$and either $\mathrm{Car}^{\bullet}, \mathrm{Chl}^{\bullet+}, \mathrm{Car}^{\bullet+}$, or oxidized Cyt $b_{559}$. Cyt $b_{559}$, which has the lowest reduction potential, is the preferred and terminal secondary electron donor within PSII. When Cyt $b_{559}$ is preoxidized, one $\mathrm{Car}^{\bullet}, \mathrm{Chl}^{\bullet+}$, or $\mathrm{Car}^{\bullet+}$ 
intermediate is observed per PSII center upon illumination. The relative amounts of these radicals generated in a PSII sample are affected by temperature (Tracewell and Brudvig 2003) and by sample conditions (Hanley et al. 1999). If there were one accessible cofactor with the lowest reduction potential in each PSII center, a single radical would be generated, rather than a distribution. Therefore, the cofactors must be closely spaced in redox potential and have good connectivity to result in different radicals being trapped in different PSII centers. The D2-G47W, D2-G47F, and D2T50F mutations are located near the headgroup of $\mathrm{Car}_{\mathrm{D} 2}$ and are expected to perturb $\mathrm{Car}_{\mathrm{D} 2}$ sterically, while the $\mathrm{F}$ and $\mathrm{W}$ residues may also participate in $\pi$ stacking. These changes may affect the stability of $\mathrm{Car}_{\mathrm{D} 2}^{\bullet+}$ relative to the other redoxactive $\mathrm{Car}$ and $\mathrm{Chl}$ cofactors, because their redox potentials are so closely spaced.

It is known that there are at least two redox-active Car (Tracewell and Brudvig 2003; Telfer et al. 2003), and five redox-active Chl (Tracewell and Brudvig 2008) in the secondary electron-transfer pathways of PSII. However, the sequence of electron-transfer events and the specific identity of Car and Chl cofactors in the pathway are unknown (Faller et al. 2001). The effect of perturbing $\mathrm{Car}_{\mathrm{D} 2}$ on the rates and yields $\mathrm{Chl}^{\bullet+}$ and $\mathrm{Car}^{\bullet+}$ formation will depend on the connectivity of $\mathrm{Car}_{\mathrm{D} 2}$ with the other redox cofactors in the secondary electron-transfer pathway. For example, if another redox cofactor were capable of donating an electron to $\mathrm{P}_{680}^{\circ+}$ on an appropriate timescale, then the effect of perturbing $\mathrm{Car}_{\mathrm{D} 2}$ could be negligible. However, in each of the mutated PSII samples (D2-G47W, D2-G47F, and D2-T50F), a substantial decrease in yield of the secondary donors is observed by near-IR spectroscopy (Fig. 4A). Therefore, $\mathrm{Car}_{\mathrm{D} 2}$ seems to act as a bottleneck, resulting in decreased yield of the Car ${ }^{\bullet}$ peak at $750 \mathrm{~nm}$, the $\mathrm{Chl}^{\circ+}$ peak from 800 to $840 \mathrm{~nm}$, and the $\mathrm{Car}^{\bullet+}$ peak near $1,000 \mathrm{~nm}$ in all mutated PSII samples. Thus, there is no efficient alternative pathway for transferring electrons to $\mathrm{P}_{680}^{\bullet+}$. Similarly, as observed by EPR spectroscopy around the $g=2$ region, the kinetics of formation for the secondary donor radicals are much slower in the G47F and G47W-mutated PSII samples than in the WT sample, although they are comparable to WT in the T50Fmutated PSII sample, which was modeled as having the smallest perturbation to $\mathrm{Car}_{\mathrm{D} 2}$ (Fig. 9). The G47F and G47W-mutated PSII samples are less efficient at forming a charge separation between $\mathrm{Q}_{\mathrm{A}}^{-}$and the secondary donors, indicating that $\mathrm{Car}_{\mathrm{D} 2}$ is involved in this process. The decreased yield and impaired kinetics of the mutated PSII samples indicate that $\mathrm{Car}_{\mathrm{D} 2}$ is an early intermediate in secondary electron transfer, consistent with $\mathrm{Car}_{\mathrm{D} 2}$ being the initial electron donor to $\mathrm{P}_{680}$ and the initial step in an extended "branched" secondary electron-transfer pathway.

In addition to the decreased overall radical yield, there is a specific perturbation of the near-IR spectrum in each mutated PSII sample: the maximum of the $\mathrm{Car}^{\bullet+}$ peak is shifted to slightly longer wavelengths (Fig. 4B), while the maxima of the $\mathrm{Chl}^{\bullet+}$ and $\mathrm{Car}^{\bullet}$ peaks remain unchanged. This indicates that the Car is not generated from $\mathrm{Car}_{\mathrm{D} 2}$, but most likely from a Car with a nearby proton accepting amino acid residue, as previously proposed (Gao et al. 2009). Furthermore, when the $\mathrm{Car}^{{ }^{+}}$peak is deconvoluted into two Gaussian components, each corresponding to a redox-active $\mathrm{Car}^{\circ+}$ (Tracewell and Brudvig 2003), the shorter-wavelength component shifts significantly more than the longer-wavelength component (more than three times, see Table 1). In WT PSII, the shorter-wavelength component has a maximum at $980 \mathrm{~nm}$ and a FWHM of $37.9 \mathrm{~nm}$, and is the dominant contribution to the $\mathrm{Car}^{\bullet+}$ peak at $20 \mathrm{~K}$. It decays much more quickly than the longerwavelength component, although it remains the dominant contribution to the peak over $8 \mathrm{~h}$ of dark decay, indicating that it is closer to $\mathrm{Q}_{\mathrm{A}}^{-}$than is the other $\mathrm{Car}^{\bullet+}$. We assign this faster-decaying, shorter-wavelength component with a maximum at $980 \mathrm{~nm}$ to $\mathrm{Car}_{\mathrm{D} 2}^{\circ}$. Although $\mathrm{Car}_{\mathrm{D} 2}$ has been proposed to be the initial electron donor in the pathway of secondary electron transfer (Lakshmi et al. 2003; Tracewell and Brudvig 2003), the specific spectral perturbations of site-directed mutations near $\mathrm{Car}_{\mathrm{D} 2}$ on the $980 \mathrm{~nm} \mathrm{Car}{ }^{\circ+}$ species provide the first direct evidence that $\mathrm{Car}_{\mathrm{D} 2}$ is one of the redox-active Car in PSII.

Previous studies have shown that the maximum of the $\mathrm{Car}^{\bullet+}$ near-IR peak shifts to a slightly shorter wavelength when $Y_{D}$ is oxidized to $Y_{D}^{\bullet}$ in all PSII centers (Tracewell and Brudvig 2003). It was hypothesized that this was either due to an electrochromic shift caused by $Y_{D}$ or due to biasing electron transfer so that the redox-active Car closest to $\mathrm{Y}_{\mathrm{D}}^{\bullet}$ would remain reduced to avoid electrostatic repulsion. However, it has been observed that electrochromic shifts propagate substantial distances through PSII. For example, generating $\mathrm{Q}_{\mathrm{A}}^{-}$affects the visible spectrum of $\mathrm{B}_{\mathrm{A}}$, the accessory Chl near $\mathrm{P}_{\mathrm{A}}$ of $\mathrm{P}_{680}$, from $21 \AA$ away, and also possibly affects the spectrum of $B_{B}$, $29 \AA$ away (Stewart et al. 2000). Although $\mathrm{Y}_{\mathrm{D}}^{\bullet}$ would most likely have a smaller electrochromic effect than $\mathrm{Q}_{\mathrm{A}}^{-}$, its effects do propagate at least as far as $\mathrm{P}_{680}$ (Diner and Rappaport 2002). $\mathrm{Car}_{\mathrm{D} 2}$ is approximately $25 \AA$ from $\mathrm{Y}_{\mathrm{D}}$. Alternatively, there are several Car cofactors in CP47 that are at a comparable or even shorter distance from $\mathrm{Y}_{\mathrm{D}}$; one Car in CP47 is $21 \AA$ from $Y_{D}$, another is $27 \AA$ away, and two others are about $30 \AA$ from $Y_{D}$. Due to closely spaced distances, an electrochromic shift would not be a definitive indicator of which Car is oxidized, even if it were observable at those distances. It is also possible that oxidation of $Y_{D}$ may bias the path of secondary electron transfer. To pull an electron from one of the Car in CP47, two intermediate $\mathrm{Chl}^{\bullet+}$ would be involved that are each $20 \AA$ from $\mathrm{Y}_{\mathrm{D}}^{\bullet}$, to ultimately generate a terminal $\mathrm{Car}^{\bullet+}$ that may be as 
close as $21 \AA$ to $\mathrm{Y}_{\mathrm{D}}^{\circ}$. Under these conditions, the $980 \mathrm{~nm}$ $\mathrm{Car}_{\mathrm{D} 2}^{\circ+}$ may be a more stable radical than the $999 \mathrm{~nm} \mathrm{Car}^{\bullet+}$, resulting in a net shift of the $\mathrm{Car}^{\bullet+}$ peak to a shorter wavelengths.

The near-IR spectra of D2-G47W, D2-G47F, and D2T50F PSII samples contain a relatively larger amount of the $\mathrm{Chl}^{\bullet+}$ peak as compared to the $\mathrm{Car}^{\bullet+}$ peak than WT PSII samples (Fig. 4B). One possibility is that the mutations around the headgroup of $\mathrm{Car}_{\mathrm{D} 2}$ caused a shift of the reduction potential of $\mathrm{Car}_{\mathrm{D} 2}^{\circ+}$ to a higher value, making it more difficult to oxidize $\mathrm{Car}_{\mathrm{D} 2}$ relative to other $\mathrm{Chl}$ and Car cofactors. This would destabilize $\mathrm{Car}_{\mathrm{D} 2}^{\bullet+}$, which is the predominant donor in the charge separation $(980 \mathrm{~nm}$ $\mathrm{Car}^{\bullet+}$, see Fig. 5; Table 1), thus favoring $\mathrm{Chl}^{\bullet+}$ in a greater portion of PSII centers. This model can explain the observations for the G47F PSII sample, which has both a lower yield of $\mathrm{Car}_{\mathrm{D} 2}^{\bullet+}$ relative to the other $\mathrm{Car}^{\circ+}$ and also a higher yield of $\mathrm{Chl}^{\bullet+}$. Alternatively, the mutations around the headgroup of $\mathrm{Car}_{\mathrm{D} 2}$ and its change in conformation may have affected the distances to other cofactors, biasing the electron-transfer pathway in a different direction, such as towards CP47, which is adjacent to the mutations and contains an extended cluster of $\mathrm{Chl}$ relatively close to $\mathrm{Car}_{\mathrm{D} 2}$ (Fig. 2). This model can explain the observations for the G47W PSII sample, which has the largest relative amount of $\mathrm{Chl}^{\bullet+}$ and also has the most $\mathrm{Car}_{\mathrm{D} 2}^{\bullet+}$ compared to the other $\mathrm{Car}^{\bullet+}$. It is likely that a combination of these factors occurs. Regardless, the relative $\mathrm{Chl}^{\bullet+}$ radical yield is higher in each of the mutated PSII samples.

The mutated PSII samples isolated from cells grown at higher light exhibit a dark-stable radical observed by EPR spectroscopy (Fig. 7). The dark-stable radical has the appearance of an organic radical, and could be either a $\mathrm{Chl}^{\bullet+}$ or $\mathrm{Car}^{\bullet+}$, although it is unusual in that it persists on ice for more than 2 min in the dark. However, a similar observation has been made for PSII samples subjected to photoinhibitory illumination (Blubaugh et al. 1991). The G47F PSII sample has the largest amount of the dark-stable radical, and it also has the slowest kinetics of charge separation. Therefore, it is possible that the dark-stable radical is associated with a quenching state, such that there is a decrease in the stability and efficiency of charge separation (Schweitzer and Brudvig 1997).

In addition, the shape of the $\mathrm{Chl}^{\bullet+}$ peak appears to depend on the light exposure during growth. The PSII samples isolated from G47W cells grown at $10 \mu$ Einsteins $/ \mathrm{m}^{2} / \mathrm{s}$, and from T50F cells grown at $10 \mu$ Einsteins $/ \mathrm{m}^{2} / \mathrm{s}$ show a double $\mathrm{Chl}^{\circ+}$ peak with maxima at 812 and $826 \mathrm{~nm}$. Conversely, PSII isolated from G47F cells grown at $40 \mu$ Einsteins $/ \mathrm{m}^{2} / \mathrm{s}$ and from T50F cells grown at $40 \mu$ Einsteins $/ \mathrm{m}^{2} /$ s only display one $\mathrm{Chl}^{\bullet+}$ peak. Moreover, the G47F and T50F PSII samples from cells grown under $40 \mu$ Einsteins/ $\mathrm{m}^{2} / \mathrm{s}$ of illumination contain the largest amounts of the dark- stable radical. This suggests that the dark-stable radical may reflect a bias in the pathways of secondary electron transfer such that fewer Chl cofactors are oxidized in PSII samples isolated from cells grown under high light than those grown under lower light conditions. The $\mathrm{Chl}^{\bullet+}$ peak in WT PSII also appears to have only one peak, but it is broader than the single peak in T50F and G47F PSII samples. It seems that the double $\mathrm{Chl}^{-+}$peak is observed for cells grown under lower light. A double $\mathrm{Chl}^{\bullet+}$ peak has been previously observed for spinach PSII, but not for Synechocystis PCC 6803 PSII (Tracewell et al. 2001). Perhaps the double versus single $\mathrm{Chl}^{\bullet+}$ peak correlates in some way with photodamage and/or photoprotection, rather than an intrinsic species difference.

The $\mathrm{Car}^{-+}$near-IR absorption peak is wider in the mutated PSII samples relative to WT PSII samples, an indication that the $\mathrm{Car}^{\bullet+}$ population may have become less homogeneous as a result of the mutations. The G47W and T50F PSII samples have the widest $\mathrm{Car}^{\bullet+}$ peaks (Fig. 4). These wider peaks may be an indication that more than one longer-wavelength $\mathrm{Car}^{\bullet+}$ contributes to the peak; because the longer-wavelength $\mathrm{Car}^{\bullet+}$ arise from a charge separation that is more stable than that involving $\mathrm{Car}_{\mathrm{D} 2}^{\circ}$, they would include components that are located further from $\mathrm{Q}_{\mathrm{A}}^{-}$than $\mathrm{Car}_{\mathrm{D} 2}$. Using high-frequency saturation-recovery EPR experiments, it has been found that the average distance from the nonheme iron to $\mathrm{Car}^{\bullet+}$ is $38 \pm 1 \AA$ (Lakshmi et al. 2003). Because $\mathrm{Car}_{\mathrm{D} 2}^{\bullet+}$ is $36 \AA$ from the nonheme iron, we can hypothesize that other candidate $\mathrm{Car}^{\bullet+}$ would be located about $40 \AA$ from the nonheme iron. There are three Car molecules that are $40 \AA$ from the nonheme iron: $\mathrm{Car}_{\mathrm{D} 1}$, a Car located at the interface of CP43 and PsbZ, and a Car located at the interface of CP47 and PsbM. There is previous evidence that $\mathrm{Chl}_{\mathrm{ZD} 1}$, which is adjacent to $\mathrm{Car}_{\mathrm{D} 1}$, can be oxidized (Stewart et al. 1998). $\mathrm{Car}_{\mathrm{D} 1}$ oxidation is also observed in isolated PSII reaction centers, containing the subunits D1, D2, Cyt $b_{559}$, and PsbI (Telfer et al. 1991). However, the two Car located at interfaces $40 \AA$ from the nonheme iron are further from $\mathrm{Q}_{\mathrm{A}}^{-}$, and would, therefore, recombine more slowly than $\mathrm{Car}_{\mathrm{D} 2}^{\circ}$, and are also located near lipids that may have an affect on their redox potential (Tracewell and Brudvig 2008). More evidence is required to identify the precise location of the longer-wavelength absorbing $\mathrm{Car}^{\bullet+}$. However, the shorter-wavelength $\mathrm{Car}^{\bullet+}$ component, with a maximum at $980 \mathrm{~nm}$ in WT, is $\mathrm{Car}_{\mathrm{D} 2}^{\circ}$, as indicated by the significant shift of its wavelength maximum following a mutation around the headgroup of $\operatorname{Car}_{\mathrm{D} 2}$.

Acknowledgments This study was supported by a grant from the DOE, Office of Basic Energy Sciences, Division of Chemical Sciences, DE-FG02-05ER15646 (G.W.B.), by a National Institutes of Health predoctoral traineeship, GM08283 (K.E.S.), and by the Engineering and Physical Sciences Research Council (EPSRC, EP/F00270X/1) 
and the Biotechnology and Biological Sciences Research Council (BBSRC, BB/C507037) (P.J.N.).

Open Access This article is distributed under the terms of the Creative Commons Attribution License which permits any use, distribution, and reproduction in any medium, provided the original author(s) and the source are credited.

\section{References}

Barry BA, Babcock GT (1998) Characterization of the tyrosine radical involved in photosynthetic oxygen evolution. Chem Scr 28A:117-122

Bautista JA, Tracewell CA, Schlodder E, Cunningham FX, Brudvig GW, Diner BA (2005) Construction and characterization of genetically modified Synechocystis sp. PCC 6803 photosystem II core complexes containing carotenoids with shorter $\pi$-conjugation than $\beta$-carotene. J Biol Chem 280:38839-38850

Blubaugh DJ, Atamian M, Babcock GT, Golbeck JH, Cheniae GM (1991) Photoinhibition of hydroxylamine-extracted photosystem II membranes: identification of the sites of photodamage. Biochemistry 30:7586-7597

Boehm M, Romero E, Reisinger V, Yu J, Komenda J, Eichacker LA, Dekker JP, Nixon PJ (2011) Investigating the early stages of photosystem II assembly in Synechocystis sp. PCC 6803. J Biol Chem 286:14812-14819

Borg DC, Fajer J, Felton RH, Dolphin D (1970) The $\pi$-cation radical of chlorophyll $a$. Proc Natl Acad Sci USA 67:813-820

Buser CA, Diner BA, Brudvig GW (1992) Photooxidation of cytochrome $b_{559}$ in oxygen-evolving photosystem II. Biochemistry $31: 11449-11459$

de Paula JC, Innes JB, Brudvig GW (1985) Electron transfer in photosystem II at cryogenic temperatures. Biochemistry 24:8114-8120

Diner BA, Rappaport F (2002) Structure, dynamics, and energetics of the primary photochemistry of photosystem II of oxygenic photosynthesis. Annu Rev Plant Biol 53:551-580

Emsley P, Cowtan K (2004) Coot: model-building tools for molecular graphics. Acta Crystallogr 60:2126-2132

Faller P, Pascal A, Rutherford AW (2001) $\beta$-Carotene redox reactions in photosystem II: electron transfer pathway. Biochemistry 40:6431-6440

Gao Y, Shinopoulos KE, Tracewell CA, Focsan AL, Brudvig GW, Kispert LD (2009) Formation of carotenoid neutral radicals in photosystem II. J Phys Chem B 113:9901-9908

Gerken S, Dekker JP, Schlodder E, Witt HT (1989) Studies on the multiphasic charge recombination between chlorophyll $a_{\mathrm{II}}^{+}$ $\left(\mathrm{P}-680^{+}\right)$and plastoquinone $\mathrm{Q}_{\mathrm{A}}^{-}$in photosystem II complexes. Ultraviolet difference spectrum of Chl- $a_{\mathrm{II}}^{+} / \mathrm{Chl}-a_{\mathrm{II}}$. Biochim Biophys Acta: Bioenergetics 977:52-61

Hanley J, Deligiannakis Y, Pascal A, Faller P, Rutherford AW (1999) Carotenoid oxidation in photosystem II. Biochemistry 38:8189_ 8195

Holzwarth AR, Müller MG, Reus M, Nowaczyk M, Sander J, Rögner M (2006) Kinetics and mechanism of electron transfer in intact photosystem II and in the isolated reaction center: pheophytin is the primary electron acceptor. Proc Natl Acad Sci USA 103:6895-6900

Kirilovsky D, Kerfeld CA (2012) The orange carotenoid protein in photoprotection of photosystem II in cyanobacteria. Biochim Biophys Acta: Bioenergetics 1817:158-166

Lakshmi KV, Reifler MJ, Chisholm DA, Wang JY, Diner BA, Brudvig GW (2002) Correlation of the cytochrome $c_{550}$ content of cyanobacterial photosystem II with the EPR properties of the oxygen-evolving complex. Photosynth Res 72:175-189
Lakshmi KV, Poluektov OG, Reifler MJ, Wagner AM, Thurnauer MC, Brudvig GW (2003) Pulsed high-frequency EPR study on the location of carotenoid and chlorophyll cation radicals in photosystem II. J Am Chem Soc 125:5005-5014

Loll B, Kern J, Saenger W, Zouni A, Biesiadka J (2005) Towards complete cofactor arrangement in the $3.0 \AA$ resolution structure of photosystem II. Nature 438:1040-1044

Metz JG, Nixon PJ, Rogner M, Brudvig GW, Diner BA (1989) Directed alteration of the D1 polypeptide of photosystem II: evidence that tyrosine-161 is the redox component, $\mathrm{Z}$, connecting the oxygen-evolving complex to the primary electron donor, $\mathrm{P}_{680}$. Biochemistry 28:6960-6969

Nixon PJ, Boehm M, Michoux F, Yu J, Komenda J (2010) Recent advances in understanding the assembly and repair of Photosystem II. Ann Bot 106:1-16

Niyogi KK (1999) Photoprotection revisited: genetic and molecular approaches. Annu Rev Plant Phys 50:333-359

Noren GH, Boerner RJ, Barry BA (1991) EPR characterization of an oxygen-evolving photosystem II preparation from the transformable cyanobacterium Synechocystis 6803. Biochemistry 30:3943-3950

Rappaport F, Diner BA (2008) Primary photochemistry and energetics leading to the oxidation of the (Mn)4Ca cluster and to the evolution of molecular oxygen in photosystem II. Coordin Chem Rev 252:259-272

Reinman S, Mathis P, Conjeaud H, Stewart A (1981) Kinetics of reduction of the primary donor of photosystem II. Influence of $\mathrm{pH}$ in various preparations. Biochim Biophys Acta: Bioenergetics 635:429-433

Schweitzer RH, Brudvig GW (1997) Fluorescence quenching by chlorophyll cations in photosystem II. Biochemistry 36:11351-11359

Shinopoulos KE, Brudvig GW (2012) Cytochrome $b_{559}$ and cyclic electron transfer within photosystem II. Biochim Biophys Acta: Bioenergetics 1817:66-75

Siegbahn PEM (2006) O-O bond formation in the S4 state of the oxygen-evolving complex in photosystem II. Chem Eur J 12:9217-9227

Sproviero EM, Gascón JA, McEvoy JP, Brudvig GW, Batista VS (2008) Computational studies of the $\mathrm{O}_{2}$-evolving complex of photosystem II and biomimetic oxomanganese complexes. Coordin Chem Rev 252:395-415

Stewart DH, Brudvig GW (1998) Cytochrome $b_{559}$ of photosystem II. Biochim Biophys Acta: Bioenergetics 1367:63-87

Stewart DH, Cua A, Chisholm DA, Diner BA, Bocian DF, Brudvig GW (1998) Identification of histidine 118 in the D1 polypeptide of photosystem II as the axial ligand to chlorophyll $\mathrm{Z}$. Biochemistry 37:10040-10046

Stewart DH, Nixon PJ, Diner BA, Brudvig GW (2000) Assignment of the $\mathrm{Q}_{\mathrm{y}}$ absorbance bands of photosystem II chromophores by low-temperature optical spectroscopy of wild-type and mutant reaction centers. Biochemistry 39:14583-14594

Tan Q, Kuciauskas D, Lin S, Stone S, Moore AL, Moore TA, Gust D (1997) Dynamics of photoinduced electron transfer in a carotenoid-porphyrin-dinitronaphthalenedicarboximide molecular triad. J Phys Chem B 101:5214-5223

Tang XS, Chisholm DA, Dismukes GC, Brudvig GW, Diner BA (1993) Spectroscopic evidence from site-directed mutants of Synechocystis PCC6803 in favor of a close interaction between histidine 189 and redox-active tyrosine 160, both of polypeptide D2 of the photosystem II reaction center. Biochemistry 32:13742-13748

Telfer A, He W-Z, Barber J (1990) Spectral resolution of more than one chlorophyll electron donor in the isolated photosystem II reaction centre complex. Biochim Biophys Acta: Bioenergetics 1017:143-151 
Telfer A, De Las Rivas J, Barber J (1991) $\beta$-Carotene within the isolated photosystem II reaction centre: photooxidation and irreversible bleaching of this chromophore by oxidised P680. Biochim Biophys Acta: Bioenergetics 1060:106-114

Telfer A, Frolov D, Barber J, Robert B, Pascal A (2003) Oxidation of the two $\beta$-carotene molecules in the photosystem II reaction center. Biochemistry 42:1008-1015

Thompson LK, Brudvig GW (1988) Cytochrome $b_{559}$ may function to protect photosystem II from photoinhibition. Biochemistry 27:6653-6658

Thompson LK, Miller AF, Buser CA, de Paula JC, Brudvig GW (1989) Characterization of the multiple forms of cytochrome $b_{559}$ in photosystem II. Biochemistry 28:8048-8056

Tracewell CA, Brudvig GW (2003) Two redox-active $\beta$-carotene molecules in photosystem II. Biochemistry 42:9127-9136

Tracewell CA, Brudvig GW (2008) Multiple redox-active chlorophylls in the secondary electron-transfer pathways of oxygenevolving photosystem II. Biochemistry 47:11559-11572
Tracewell CA, Cua A, Stewart DH, Bocian DF, Brudvig GW (2001) Characterization of carotenoid and chlorophyll photooxidation in photosystem II. Biochemistry 40:193-203

Umena Y, Kawakami K, Shen JR, Kamiya N (2011) Crystal structure of oxygen-evolving photosystem II at a resolution of $1.9 \AA$. Nature 473:55-60

Un S, Tang XS, Diner BA (1996) $245 \mathrm{GHz}$ high-field EPR study of tyrosine- $\mathrm{D}^{\circ}$ and tyrosine- $\mathrm{Z}^{\circ}$ in mutants of photosystem II. Biochemistry 35:679-684

Vermeglio A, Mathis P (1974) Light-induced absorbance changes at $-170{ }^{\circ} \mathrm{C}$ with spinach chloroplasts: charge separation and field effect. Biochim Biophys Acta: Bioenergetics 368:9-17

Vrettos JS, Stewart DH, de Paula JC, Brudvig GW (1999) Lowtemperature optical and resonance Raman spectra of a carotenoid cation radical in photosystem II. J Phys Chem B 103:6403-6406 